\title{
Who goes home? Predictive factors in stroke recovery
}

\author{
SUSAN HENLEY, SYLVIA PETTIT, ANDREW TODD-POKROPEK, \\ ANNEMARIE TUPPER
}

From University College Hospital, London, UK

SUMMARY One hundred and seventy two stroke patients were assessed two weeks post-stroke by a multi-disciplinary team. The predictive ability of a number of variables, including social, psychological and physical factors, was estimated for four outcome groups. Highly significant factors for good and bad outcome for one year were identified.

Cerebrovascular disease is the third major cause of death in developed countries. It is the most frequent cause of chronic disability in the UK, ${ }^{1}$ necessitating a great deal of care involving human and material resources. A study was planned to investigate whether it was possible to predict, on the basis of simple assessments in the early stages of illness, the probable outcome of a patient's stroke in practical terms with regard to his future needs. It was thought likely that factors other than the purely clinical ones might play a part and a multidisciplinary team consisting of a doctor, psychologist, physiotherapist and occupational therapist seemed appropriate. The help of a statistical expert was also provided throughout the project. Clinical features indicative of early death in the acute stage are well known. ${ }^{2}$ Our main interest was in the possibility of differentiating between patients likely to achieve domestic and/or personal independence to the extent of becoming able to live in the community and those needing long term institutional care. We also wished to determine what, if any, effect rehabilitative treatment has on the course of recovery and outcome.

\section{Patients}

We considered 286 patients admitted between April 1979 and April 1981 to University College Hospital with a probable diagnosis of recent stroke, as well as those patients who developed a stroke while in hospital. As far as possible, informed consent was obtained from the patients themselves or from relatives. Of those considered, 79 were found to have a neurological deficit not due to a recent cerebrovascular accident (mainly long-standing hemiplegia, or transient ischaemic attacks). Eight were transferred for neurosurgery or left the country, two were lost to follow-up and one

Address for reprint requests: Dr Annemarie Tupper, University College Hospital, Gower Street, London WCIE 6AU, UK.

Received 29 November 1983 and in final revised form 7 June 1984. Accepted 16 June 1984 patient refused consent. Of the remaining 196 patients, 24 died before the first assessment could be completed and were excluded from the final analysis. This left 172 patients, 82 men and 90 women; $13 \%$ were aged between 45 and $60 \mathrm{yr}$; $60 \%$ were aged between 61 and $80 \mathrm{yr}$; and $27 \%$ over $80 \mathrm{yr}$.

\section{Method}

Each of these 172 patients was assessed on four occasions. For technical reasons only 59 were studied by computed tomography (CT). Basic personal and social information, such as age, sex, occupation, socio-economic group, marital status, housing, frequency of social contact, and previous level of independence as well as family history, associated disorders, previous drug treatment and facts relating to the recent stroke, were recorded. Mental function was assessed with particular attention to level of consciousness, speech, thought disorder, perseveration, verbal learning and visuospatial ability, body concept, apraxia, agnosia and sensory neglect.

As we intended to see patients at a very early stage, assessments had to be reasonably quick and simple to avoid overtiring patients with consequent loss of concentration and co-operation. For this reason formal speech assessments were considered unsuitable and we merely graded the patient's ability to communicate intelligibly and noted the presence of dysphasia or dysarthria. Motor and sensory function was assessed using a modification of the Northwick Park (Motor Club) scales. ${ }^{3}$ This included a functional mobility test, consisting of 13 activities following a basic developmental pattern of total body movement and balance (rolling to right or left, bridging, sitting, touching the floor and returning to sitting position, standing up from sitting, standing on right and left leg and both together, transfer from bed to chair and back, walk 15 metres and climb up and down 10 steps). A numerical score for each activity was derived from the ability to carry it out independently (3), with aids (2), with personal assistance (1) or not at all except with two or more helpers $(0)$. These scores were considered individually and in total, the maximum total score possible being 39 .

Activities of daily living were assessed using a three point scale taking account of aids or help required for a given task. Mood was rated on a five point scale by the psychologist. Available scales, considered less than satisfactory at the best 
Table 1 Death as a function of age, sex and time

\begin{tabular}{|c|c|c|c|}
\hline Age $(y r)$ & No of Patients & $\%$ of Total & Death rate $\%$ \\
\hline $\begin{array}{l}45-60 \\
61-80 \\
>80 \\
\text { Males } \\
\text { Females }\end{array}$ & $\begin{array}{r}22 \\
103 \\
47 \\
82 \\
90\end{array}$ & $\begin{array}{l}13 \% \\
60 \% \\
27 \% \\
48 \% \\
52 \%\end{array}$ & $\begin{array}{l}14 \% \\
33 \% \\
58 \% \\
27 \% \\
43 \%\end{array}$ \\
\hline $\begin{array}{l}\text { Time } \\
0-2 \text { week } \\
2-6 \text { week } \\
6 \text { week }-6 \text { month } \\
6 \text { month-1 yr }\end{array}$ & $\begin{array}{l}22 \\
11 \\
18 \\
11\end{array}$ & $\begin{array}{r}13 \% \\
6 \% \\
11 \% \\
6 \%\end{array}$ & $\begin{array}{l}35 \% \\
18 \% \\
29 \% \\
18 \%\end{array}$ \\
\hline
\end{tabular}

of times, were considered inappropriate, especially for dysphasic or confused patients. Assessment of verbal learning was based on performance on two short paired associate learning tests of different degrees of complexity; that of visuo-spatial ability on scores on the Block Design subtest of the Wechsler Adult Intelligence Scale (WAIS). Sensorymotor co-ordination was assessed by a timed test of inserting metal rods into holes. Motivation is difficult to assess and validated assessments are lacking. However, in view of its likely importance we decided to estimate it using a consensus opinion of the research and treating therapists with particular attention to the patient's willingness to attend treatment sessions as well as his general attitude to his present and future state and reliance on others. In most cases the therapists, who also had discussions with the nursing staff, had no difficulty in deciding whether or not a patient was well motivated towards his rehabilitation.

For statistical analysis it was judged better to have a small number of well defined categories rather than a larger number of poorly defined ones, and a crude classification into four grades of outcome appeared suitable:

Grade I Independent with or without domestic assistance

Grade II Personal assistance in own home

Grade III Institutional care

Grade IV Death

The data were processed using Statistical Package for the Social Sciences (SPSS). After validation, contingency tables were established for the different grades of outcome against the different values for the various parameters. The null hypothesis, that there was no relationship between each variable and the outcome, was tested using a chi squared statistic. The results of this test were summarised as being significant if $\mathrm{p}$ was less than 0.05 for the null hypothesis and highly significant if $p$ was less than $0 \cdot 01$. The Kruskal-Wallis non-parametric analysis of variance, ranking each given variable for groups defined in terms of outcome was also used. The null hypothesis, that there was no significant difference in rank for each of the outcome groups was tested, and gave very similar results to the chi squared statistic.

\section{Results}

Total deaths numbered $86(44 \%)$ including the 24 who died before completion of the first assessment. An analysis of mortality of the ultimate sample of 172 patients as a function of age, sex, and the time post stroke is given in table 1 .
The dominant parameter for outcome, and survival in particular, was age. In order to eliminate the effect of age when considering other variables, appropriate age-matched groups were selected. Other factors significantly related to (greater) age (see table 2 ) were sex (more women), marital state (fewer living partners), weight (more underweight patients), occupation (fewer working outside the home), and lifestyle (more domestic and personal assistance before the index stroke). In older patients strokes occurred more frequently at rest, in the younger ones more frequently during activity. Hypertension was least common in the oldest group. Outcome, in terms of the four categories outlined above was analysed both for all patients, and separately for age selected groups.

The most important factors related to early death (within 6 weeks) were prolonged coma, confusion, perseveration, conjugate gaze deviation, faecal incontinence and hypotonicity in the lower limbs.

Favourable factors in the history included a living partner, previous independence and normal or overweight. Occurrence of strokes during activity or states of high arousal carried a better prognosis than ones occurring during sleep. A history of transient ischaemic attacks was significantly related to a good outcome.

Findings during the first 2 weeks after stroke related to outcome after one year in the following ways: Consciousness: $67 \%$ of the fully alert patients returne ${ }^{\circ}$ home. None of those responding to painful stimuli only survived. Confusion: $31 \%$ died, $31 \%$ needec institutional care and $19 \%$ personal help at home Perseveration: only one patient in the best outcome $\overrightarrow{0}$ group perseverated. Fifty per cent of those of perseverating died and $20 \%$ needed institutional care. Incontinence: more than $55 \%$ of the patients with urinary and $74 \%$ of those with faecal incontinence died. Apraxia, agnosia and sensory neglect: approximately $75 \%$ of patients without these findings returned home. Mood: $80 \%$ of those even moderately cheerful did well. Speech: $27 \%$ of our sample were dysphasicover $55 \%$ of them had a good outcome. Seventy-one per cent of the patients with normal speech went home. Visual fields: were normal in half the patients. There was no significant difference in the outcome between those with and those without hemianopia.

Table 2 Variables and the significance (p) of their relationship to age

\begin{tabular}{|c|c|c|c|}
\hline $\begin{array}{l}\text { Sex } \\
\text { Marital state } \\
\text { Weight } \\
\text { Occupation } \\
\text { Life style } \\
\text { Circumstances in which } \\
\text { stroke occurred } \\
\text { Blood pressure }\end{array}$ & $\begin{array}{l}<0.01 \\
<0.01 \\
<0.01 \\
<0.01 \\
<0.01 \\
<0.01 \\
<0.01\end{array}$ & $\begin{array}{l}\text { Socio/economic } \\
\text { Housing } \\
\text { Major life event } \\
\text { Frequency of social } \\
\text { contacts } \\
\text { TIA } \\
\text { Loss of } \\
\text { consciousness }\end{array}$ & $\begin{array}{l}\text { NS } \\
\text { NS } \\
\text { NS } \\
\text { NS } \\
\text { NS }\end{array}$ \\
\hline
\end{tabular}


Table 3 Variables significantly related to outcome

\begin{tabular}{|c|c|}
\hline Good outcome & Poor outcome \\
\hline $\begin{array}{l}\text { *Living with partner } \\
\text { *High frequency of social contacts } \\
\text { *Previous independence } \\
\text { †History of TIA's }\end{array}$ & $\begin{array}{l}\text { *Advanced age } \\
\text { *Duration of coma } \\
\text { † Stroke during sleep }\end{array}$ \\
\hline $\begin{array}{l}\text { Two weeks post-stroke } \\
{ }^{*} \text { High level of consciousness } \\
\text { *Absence of visual field neglect } \\
\text { * Positive mood } \\
\text { * Normal speech } \\
\text { +Verbal learning ability } \\
\text { *Visuospatial ability } \\
\text { * Stereognosis } \\
\text { * Presence of isolated limb movements } \\
\text { * Presence of superficial touch and } \\
\text { joint position sense } \\
\text { *Upper limb sensory-motor co-ordinati } \\
\text { *High functional mobility test score } \\
\text { *Ability to perform personal activities } \\
\text { (drink, feed, dress, personal hygiene) } \\
\text { *Ability to perform domestic activities }\end{array}$ & $\begin{array}{l}\text { Two weeks post-stroke } \\
\text { †Conjugate gaze deviation } \\
\text { "Confusion } \\
\text { *Incontinence } \\
\text { *Perseveration } \\
\text { *Sensory neglect } \\
\text { +Hypotonicity } \\
\text { *Swelling of hand } \\
\text { †Swelling of foot } \\
\text { †Pain in shoulder }\end{array}$ \\
\hline
\end{tabular}

$*$ = very significant $\mathrm{p}>0.01$

$\dagger=$ significant $\quad p>0.05$

Approximately $75 \%$ of patients without visual field neglect returned home. Verbal Learning (Paired associates), Visuo-spatial ability (WAIS Block Design Test) and Motor-sensory (Handfunction Dexterity Test): high scores in these tests were associated with good outcome. Functional Mobility Assessment: scores considered individually or in combination were highly predictive indicators of final result. Out of a combined score of 39 all patients scoring better than 30 achieved full independence. Eighty-eight per cent of those who later needed institutional care scored less than 5. Individual activities were also good indicators. Patients who scored highly on individual movements, but were only able to complete one or two of them, often improved in spite of an early low total score. Activities of daily living were significantly related to outcome. Patients who could not be assessed on test requiring some attention and co-operation (for example, speech, visual field and sensory testing) had a bad prognosis. CT Scans: 59 patients were scanned. Sixtysix per cent of scans showed infarction, $8 \%$ haemorrhages, and $26 \%$ no abnormalities. Pathology, side, region, size and the presence or absence of enhancement with contrast did not relate significantly with outcome in this sample. Sixty-three per cent of the patients with marked cerebral atrophy were institutionalised or died during the following year. Hypertension: $46 \%$ of our patients gave a history of hypertension, with $63 \%$ of them having received hypotensive therapy at some time pre-stroke. Neither a history of hypertension nor resting pressure above $140 / 90$ at 2 weeks post-stroke was significantly related to outcome.
Table 4 Discriminant function variables and their weights

\begin{tabular}{lrr}
\hline & Function I & Function 2 \\
\hline Age & -0.01808 & 0.02226 \\
Marital state & -0.40832 & -0.36648 \\
Previous life style & -0.24277 & -0.38134 \\
Level of consciousness & 0.21395 & -0.26938 \\
Speech & -0.31152 & 0.46252 \\
Visual field defect & -0.02743 & -0.10653 \\
Ignoral & -0.20326 & -0.01872 \\
Incontinence & $0 \cdot 13578$ & -0.05784 \\
Sensation & -0.18696 & 0.13616 \\
Apraxia & 0.08876 & 0.43388 \\
Sitting balance & -0.62812 & -0.01808 \\
Standing balance & 0.04610 & 0.32402 \\
Mood & -0.43020 & -0.01825 \\
Visuo-spatial ability & 0.16379 & 0.21188 \\
Hand/finger swelling & -0.21230 & 0.13458 \\
Drinking & 0.96052 & 2.42639 \\
Feeding & 0.84440 & -1.43649 \\
Dressing & -0.47365 & 1.45500 \\
Use lavatory & -0.72962 & 0.59968 \\
Wash face and hands & -0.94311 & -3.09835 \\
Stereognosis & 0.40298 & -0.85422 \\
Sensory-motor co-ordination & 0.32367 & $1 \cdot 16154$ \\
affected hand & 0.32367 & \\
Sensory-motor co-ordination & -0.59970 & -0.26695 \\
both hands together & & \\
\hline
\end{tabular}

The higher the value the greater the positive $(+)$ or negative $(-)$ contribution of the variable in question to the given function.

Therapy: Early or late start of treatment-that is before or after the second week was not significantly related to outcome. The amount of physiotherapy during the first two weeks-more or less than five sessions per week-was not significantly related to outcome. However, the amount of treatment became highly significant from the sixth week onwards. Motivation towards treatment, as assessed by the therapists, was very significantly related to outcome at all stages.

Although the type of physiotherapy used undoubtedly varied according to the individual patient's problems, treatment in the early weeks was likely to be more standardised, consisting of positioning, passive movements and chest care. We have

Table 5 Numbers of cases classified by a discriminant function analysis

Predicted grade

\begin{tabular}{llll}
\hline 1 & 2 & 3 & 4 \\
\hline
\end{tabular}

\begin{tabular}{lrrrr} 
Actual Grade & & & & \\
1 & 48 & 8 & 2 & 2 \\
2 & 6 & 22 & 2 & 1 \\
3 & 2 & 2 & 10 & 4 \\
4 & 4 & 11 & 10 & 38 \\
\hline
\end{tabular}

Grade I Independent with or without domestic assistance

Grade II Personal assistance in own home

Grade III Institutional care

Grade IV Death 


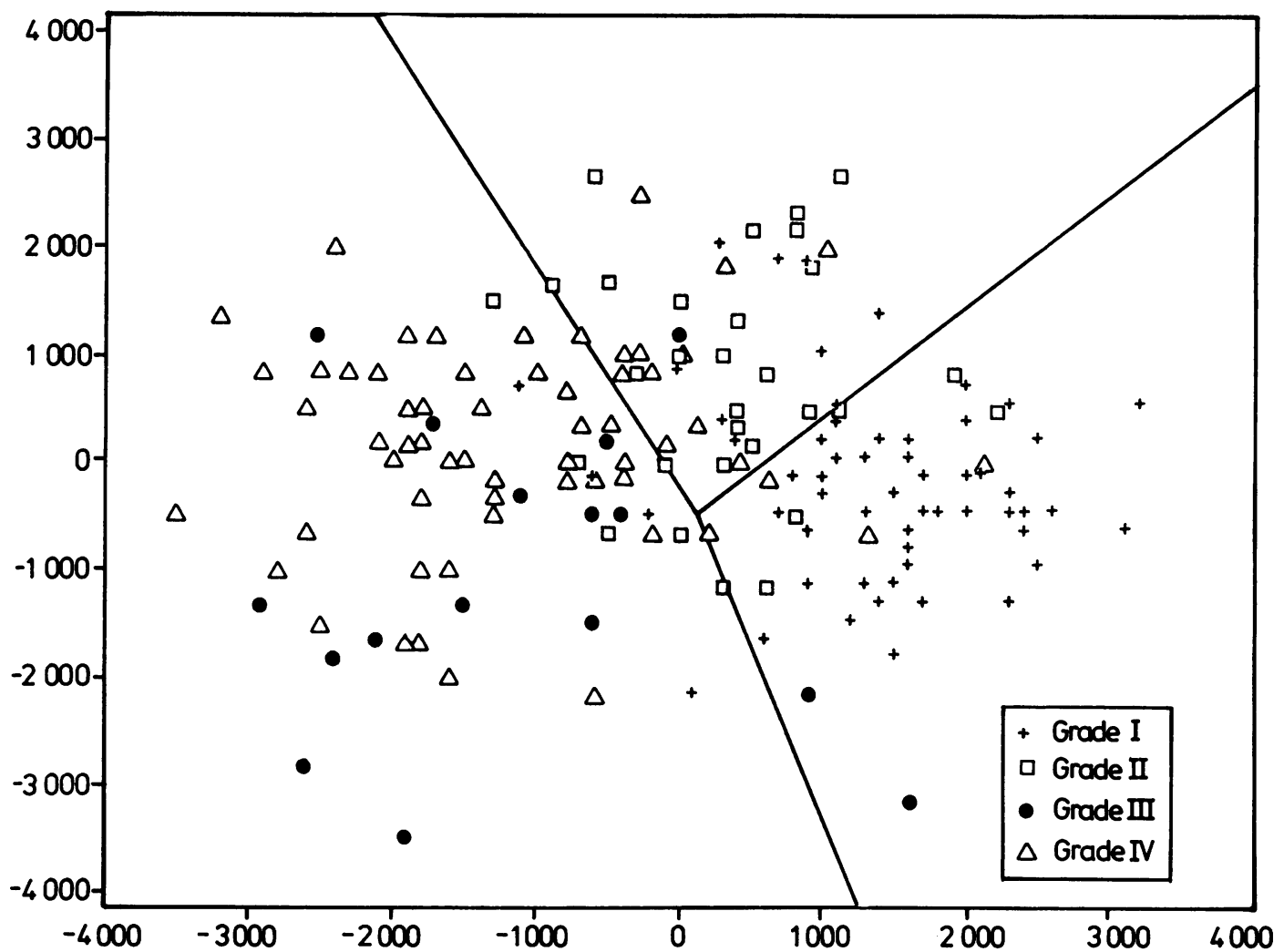

Fig A plot of discriminant score 1 (horizontal axis) versus discriminant score 2 (vertical axis) for all patients together with the lines indicating the separation between Grades I, II, and III $+I V$. Three discriminant functions were derived from the 23 variables most significantly related to outcome (see table 4). Two of these, 1 and 2 (represented by the horizontal and vertical axes respectively) accounted for $89.5 \%$ of all variance.

no evidence to suggest that, at this stage, once therapy had been requested by the medical staff, any discrimination in relation to the severity of the illness took place. It was not possible to exclude the possibility that, overall, because of some form of selection, patients with a better clinical status may have received more treatment.

A discriminant function analysis was performed on the 23 variables which appeared to be most significantly related to outcome. These are listed in table 4. The weights associated with each variable for the first two (of three) such discriminant functions derived (with which $89.5 \%$ of all variance is associated) are also listed in table 4 . Table 3 shows relationships between given variables and outcome. For these variables, differences between unselected and the largest age selected group (61-80 yr) were only minor. Table 5 shows the ability of such a discriminant analysis to classify the outcome of all cases. Entries on the diagonal are correct classifications while entries off the diagonal are incorrect classifications. Another way of looking at the analysis is given in the fig. Here the axes are the first two discriminant functions. All cases are plotted in this space, being given symbols indicating outcome. It may be observed that after this transformation, results for cases for a given outcome tend to cluster well. Lines have been drawn to indicate the classifications as made by the discriminant analysis. Thus, cases lying within one given region will be classified correspondingly. The various types of true and false classifications can thus be readily observed.

\section{Discussion}

The results show that a good outcome group can be identified with some confidence during the first two weeks after stroke, as can a group with poor outcome.

Mortality in the first 6 weeks in our series was lower than in others. This was probably due to the fact that 
patients who died during the first two weeks were not fully assessed and were therefore excluded from the final analysis. It is also possible that patients admitted to a London teaching hospital in a heavily populated area differ from those in other series where a large District Hospital provides the main inpatient facility. Our overall mortality rate of $44 \%$ after 1 year does not differ greatly from that observed in other studies in Great Britain ${ }^{4}(42 \%)$ and the USA ${ }^{5}(48 \%)$. Hypertension, a known risk factor ${ }^{6-8}$ regarding the occurrence of stroke, was said by some earlier workers ${ }^{9-11}$ to be associated with poor prognosis. It occurred in $46 \%$ of our patients and was highly related to age, fewer older patients having a history of hypertension. Like other more recent authors, ${ }^{12-14}$ we found no significant relation to outcome: $63 \%$ of our hypertensives had received hypotensive drugs at some time before stroke compared with one third in the WHO Collaborative Study. ${ }^{7}$

Patients having sustained their stroke during activity are more likely to have a good outcome. This may suggest some difference in pathology from thromboocclusive lesions occurring during sleep, when pressure falls and haemoconcentration increases, and which showed a worse outcome. It was hoped that CT scans might clarify this matter but these results were generally disappointing. This may have been because only a third of our patients were scanned, each on only one occasion which may not have been at the optimum time for showing change. ${ }^{15}$ Other workers ${ }^{16} 17$ have remarked on the difficulty of diagnosis from a single scan and commented that $20 \%-40 \%$ of clinically large infarcts did not show on scans for some weeks. A further problem we encountered was that brainstem lesions were not visualised. It is possible that the main contribution of CT scanning in strokes remains the exclusion of other treatable pathology, such as space-occupying lesions in selected patients.

An interesting negative result was the lack of any significant relationship between recent life events and outcome.

Patients who are non-assessable at an early stage on tests requiring active co-operation tend to have a poor prognosis. The reason may be impaired consciousness, impaired intellect with or without severe verbal comprehension loss and lack of co-operation or motivation, in some cases due to gross mood disturbance.

Motivation and mood state as assessed by therapists and psychologist, respectively, proved highly significant predictors of outcome in the present study, but generalisations from these results are limited by the subjective nature of the data. It is clear, however, that these are variables warranting more intensive and systematic investigation in future research.

Other workers ${ }^{18}$ have stated that in severely dis- abled stroke patients "remedial therapy continued for long periods, especially in the group who did not improve" and suggest that "rehabilitation resources should be spent more appropriately". From our findings it appears that the patient's attitudes towards and ability to co-operate with treatment is as important as the actual amount of treatment provided. It will be important to carry out a formal validation of these findings on a new series of patients. Some possible indication of the value of the present results may be gained from data obtained in the University College Hospital Stroke Rehabilitation Unit. During 1981 before the study was completed, the average stay for in-patients eventually discharged home was 9.6 weeks, while that for patients ultimately admitted to long stay accommodation was over 20 weeks. Some of the difference was due to the difficulty in arranging suitable long-stay care, some to the erroneous hope that prolonged intensive treatment in the Unit would eventually lead to successful outcome. In 1982 when the study was completed and the criteria found to relate to outcome tentatively applied to the admission policy, treatment and discharge plans in the Stroke Unit, average stay was reduced to $6 \cdot 1$ weeks for patients returning home and 8.6 weeks for those transferred to long-stay wards. There had been no other major change regarding staff or treatment methods in the Unit during this period.

We are grateful to the many patients who agreed to take part in the project and to our consultant colleagues who permitted us to study them. We would like to express our thanks to Sir James Lighthill, Professor AN Exton-Smith, Drs A Linney, M Boothroyd-Brook, the late J McFie, M Huang, E Smith, and also to Sue Clarke, Margaret Hunt, Fiona Burns and Jess Bimrah. We are indebted to Dr A Derweesh for reading the CT scans, to Caroline Sullivan for the OT Assessments and to the Special Trustees of University College Hospital for a generous grant.

\section{References}

${ }^{1}$ Harris AI, Cox E, Smith RW. Handicapped and Impaired in Great Britain 1971 HMSO.

${ }^{2}$ Oxbury JM, Greenhall RDC, Grainger KMR. Predicting the outcome of stroke: Acute stage after cerebral infarction. Br Med J 1975;3:125-7.

${ }^{3}$ Ashburn A. A physical assessment for stroke patients. Physiotherapy 1982;68:109-13.

${ }^{4}$ Brewis M, Poskanzer DC, Roland C, Miller $\mathbf{H}$. Neurological disease in an English city. Acta Neurol Scand 1966;42:1-89.

${ }^{5}$ Weinfeld FD. The national survey of stroke. Stroke 1981;12 suppl I:I1-I91.

${ }^{6}$ Herman B, Leyton ACM, Van Luisk JH, Frenken 
CWGM, Op de Coul AAW, Schulte BPM. An evaluation of risk factors for stroke in a Dutch community. Stroke 1982;13:334-9.

${ }^{7}$ Aho K, Harmsen P, Hatano S, Marquardsen J, Smirnov VE, Strasser T. Cerebrovascular disease in the community: results of a WHO collaborative study. Bull WHO 1980;58:113-30.

${ }^{8}$ Salonen JT, Puska P, Tuo Milehto J, Homan K. Relation of blood pressure, serum lipids and smoking to the risk of cerebral stroke. Stroke 1982;13:327-33.

${ }^{9}$ Marquardsen J. The natural history of acute cerebrovascular disease-a retrospective study of 769 patients (1940-1952). Acta Neurol Scand 1969 suppl 38;145:9-192.

${ }^{10}$ Barham Carter AB. Strokes. Proc $R$ Soc Med 1963;56:483-6.

${ }^{11}$ Marshall J, Kaeser AC. Survival after non-haemorrhaegic cerebrovascular accidents: a prospective study. $\mathrm{Br} \mathrm{Med}$ J 1961;2:73-7.

12 Feigenson JS, Fletcher H, McDowell X, Meese P, McCarthy ML, Greenberg SD. Factors influencing outcome and length of stay in a stroke rehabilitation unit. Medical and functional prognostic indicators. Stroke 1977;8:651-6.

${ }^{13}$ Abu-Zeid HAH, Nung Won Choi, Ping-Hwa Hsu, Maini KK. Prognostic factors in the survival of 1,484 stroke cases observed for $30-48$ months. Arch Neurol 1978;35:213-8.

14 Waltimo O, Kaste M, Fogelholm R. Prognosis of patients with unilateral cranial occlusion of the internal carotid artery. Stroke 1976;7:480-2.

${ }^{15}$ Masden JC, Azar-Kia R. Evaluation of recent cerebral infarction by CT. Arch Neurol 1977;34:417-21.

${ }^{16}$ Gilmore PC, Brenner RP. Correlation of EEG, CT and Clinical findings. Arch Neurol 1981;38:371-2.

${ }^{17}$ Soderstrom CE, Mettinger KL, Olivecrona H, Ericson $\mathrm{K}$. Computed tomography and CSF spectrophotometry. Scand J Rehab Med 1981;13:64-71.

${ }^{18}$ Andrews K, Brocklehurst JC, Richards B, Laycock PJ. The recovery of severely disabled stroke patients. Rheumatol Rehabil 1982;21:225-30. 